\title{
Temporal artery biopsy and corticosteroid treatment
}

\author{
M.C. ALLISON AND P. J. GALLAGHER \\ From the Royal United Hospital, Bath, Avon BA1 3NG
}

SUMMARY Eighty-four of 132 patients with clinically genuine cranial arteritis had histological evidence of inflammation at temporal artery biopsy. The highest incidence of a positive result $(82 \%)$ was in patients biopsied before corticosteroid therapy. The figure fell to $60 \%$ if corticosteroids had been given for less than a week before biopsy and $10 \%$ thereafter.

Corticosteroids rapidly suppress the subjective symptoms of cranial arteritis, but there is only anecdotal information on the value of temporal artery biopsy in patients already receiving treatment. We have reviewed the histology in patients satisfying clinical and laboratory criteria for cranial arteritis and related the findings to the duration of corticosteroid therapy before biopsy.

\section{Patients and methods}

The clinical records and temporal artery histology of 140 patients were reviewed. The timing of both the temporal artery biopsy and the start of corticosteroid therapy was recorded. Eight patients were excluded from the study because they had received doses of prednisolone below those generally accepted as being necessary to control cranial arteritis. Four of these had taken less than $25 \mathrm{mg}$ daily, 3 had developed symptoms while on a low dose of prednisolone for some other condition, and one patient was excluded because compliance with treatment was uncertain.

Biopsies were classified as typical giant cell arteritis when they showed marked intimal thickening and dense, sometimes granulomatous chronic inflammation. An essential feature was giant cell and histiocytic inflammation in relationship to disrupted elastic tissue. In a small proportion of cases giant cells were absent and those were catagorised as 'atypical' arteritis.

The essential histological features for the diagnosis of healed arteritis included residual foci of lymphocytic inflammation, vascularisation of the arterial wall,

Accepted for publication 19 September 1983.

Correspondence to Dr P. J. Gallagher, Department of Pathology, Southampton University General Hospital, Southampton SO9 4XY. fibrosis and atrophy of the muscular media, considerable loss of the elastic lamellae with associated concentric condensation of bizarre and fibrous tissue ${ }^{12}$ (Fig. 1). In contrast negative biopsies showed only

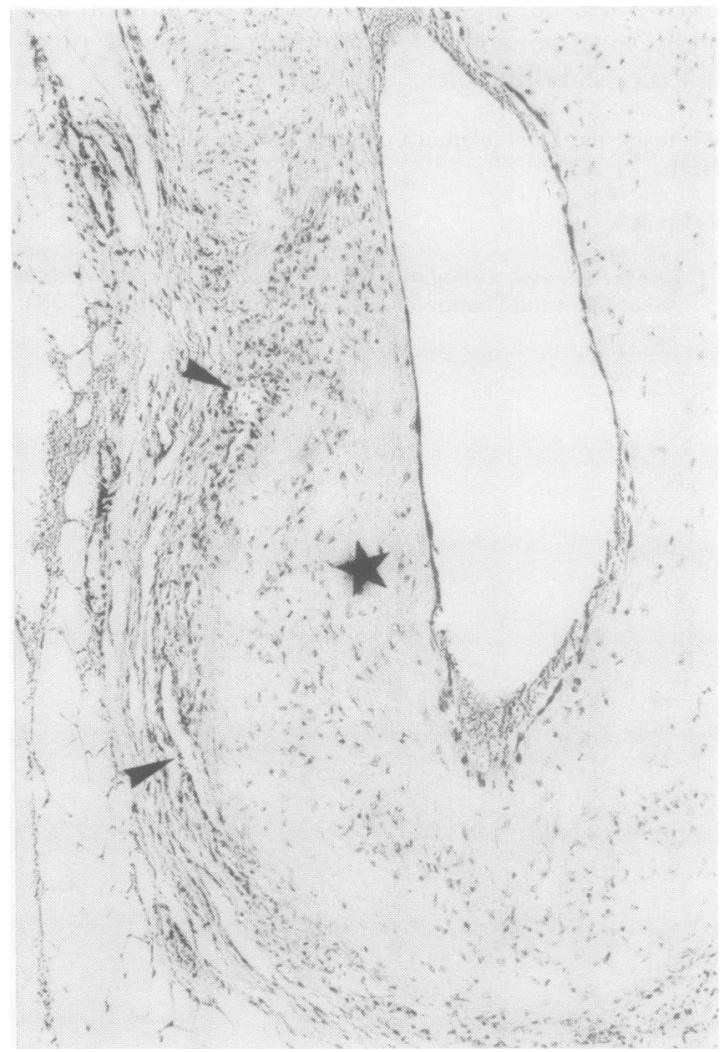

Fig. 1 Healed temporal arteritis. There is irregular intimal thickening and scarring ( $\star$ ) and ingrowth of small vessels (arrowheads). Haematoxylin and eosin, $\times 75$. 
variable degrees of concentric fibroelastic intimal thickening (Fig. 2).

Patients with negative biopsies were accepted as genuine cases of cranial arteritis when they satisfied all the following criteria: (1) raised erythrocyte sedimentation rate (ESR) or plasma viscosity (PV); (2) at least one characteristic symptom such as recent onset, temporal headache, scalp tenderness, jaw claudication, or sudden loss of vision not due to some other obvious cause; (3) ESR $>70 \mathrm{~mm} / \mathrm{h}$ or PV $>1.9$ centipoises or a second characteristic symptom; (4) rapid clinical response to corticosteroid treatment; (5) subsequently managed as cranial arteritis despite negative biopsy result.

\section{Results}

In the majority of patients temporal artery biopsy was performed either before or within a week of the start of corticosteroid treatment (see Table 1). Of the 20 patients who had been on prednisolone for more than a week 7 were biopsied in the second week, 7 at 3-6 weeks, and 6 thereafter.

Overall, 84 of the 132 patients $(64 \%)$ had positive temporal artery biopsies. However, $82 \%$ of the 61

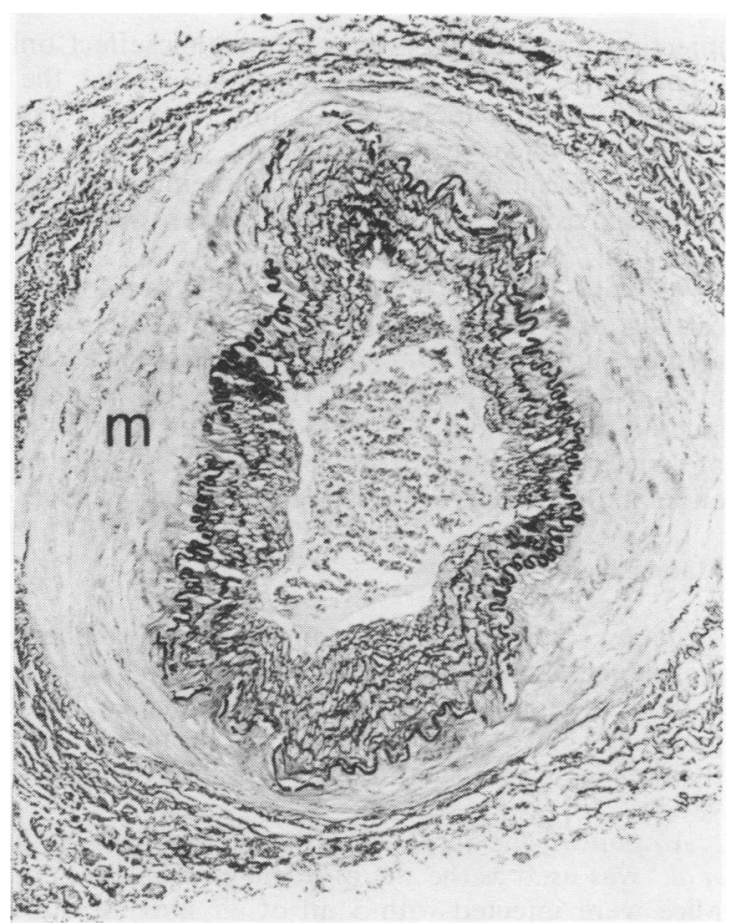

Fig. 2 Negative temporal artery biopsy. Concentric fibroelastic intimal thickening only. The media $(m)$ is unremarkable. These are the characteristic changes of 'age-related' arteriosclerosis. (Elastic-van Giesen, $\times 85$ ).
Table 1 Temporal artery biopsy histology and duration of steroid treatment

\begin{tabular}{lccc}
\hline & $\begin{array}{l}\text { No } \\
\text { Steroids }\end{array}$ & $\leqslant 1$ week & $>1$ week \\
\hline $\begin{array}{l}\text { Positive biopsy } \\
\text { Typical GCA }\end{array}$ & $42(68 \%)$ & $26(52 \%)$ & $2(10 \%)$ \\
$\begin{array}{l}\text { Atypical arteritis* } \\
\text { Healed arteritis }\end{array}$ & $-1(14 \%)$ & $4(8 \%)$ & - \\
$\begin{array}{l}\text { Negative biopsy } \\
\text { Total }\end{array}$ & $11(18 \%)$ & $-21(40 \%)$ & $16(10 \%)$ \\
& $61(100 \%)$ & $51(100 \%)$ & $20(100 \%)$ \\
\hline
\end{tabular}

GCA = giant cell arteritis

* Giant cells absent but otherwise typical of cranial arteritis.

patients biopsied before treatment had histological evidence of active inflammation. This percentage falls to $60 \%$ in the first week of treatment and $10 \%$ thereafter. The mean length of artery biopsy was $7 \cdot 9$ $\mathrm{mm}$ in the pretreatment cases and $6.2 \mathrm{~mm}$ in the corticosteroid treated patients

\section{Discussion}

The results confirm previous observations ${ }^{2}$ that there is a significant percentage of negative temporal artery biopsies even in patients with classical clinical cranial arteritis. Rather surprisingly they also suggest that a percentage of 'false negative' biopsies increases within days of a trial of corticosteroids. The obvious inference is that in a significant number of corticosteroid treated patients the inflammatory process quickly resolves both clinically and histologically. Changes diagnostic of healed arteritis were seen in only 2 biopsies. This must cast doubt on the value of temporal artery biopsy in those patients who have lost their symptoms after being treated with highdose steroids for more than a week. We emphasise that the biopsies in our series were smaller than those routinely performed in other centres, ${ }^{3}$ where $2 \mathrm{~cm}$ or more of artery are examined. It is clearly important to palpate the superficial temporal artery for areas of tenderness, especially in patients already receiving treatment. It is quite possible that serial sectioning of longer biopsies taken from these areas might yield evidence of more residual foci of active inflammation or the changes of healed arteritis.

We thank the physicians of the Royal United Hospital, Bath, the Royal National Hospital for Rheumatic Diseases, Bath, and Southmead Hospital, Bristol, for permission to study case notes. We are grateful to Drs E. W. Hall, J. V. Lever, and C. R. Tribe for access to their biospy material.

\section{References}

1 Lie J T, Brown A L, Carter E T. Spectrum of aging changes in temporal arteries. Its significance in interpretation of biopsy of the temporal artery. Arch Pathol 1970; 90: 279-85.

2 Allsop C J, Gallagher P J. Temporal artery biopsy in giant cell arteritis: a reappraisal. Am J Surg Pathol 1981; 5: 317-23.

3 Errlinger R E, Hunder G G, Ward LE. Polymyalgia rheumatica and giant cell arteritis. Ann Rev Med 1978; 29: 15. 